\title{
BMJ Open Identifying cut-off scores for job demands and job control in nursing professionals: a cross-sectional survey in Germany
}

\author{
Sabrina Zeike, ${ }^{1}$ Lena Ansmann, ${ }^{2}$ Lara Lindert, ${ }^{1}$ Christina Samel, ${ }^{3}$ \\ Christoph Kowalski, ${ }^{4}$ Holger Pfaff ${ }^{1}$
}

To cite: Zeike S, Ansmann L, Lindert L, et al. Identifying cut-off scores for job demands and job control in nursing professionals: a cross-sectional survey in Germany. BMJ Open 2018;8:e21366. doi:10.1136/ bmjopen-2017-021366

- Prepublication history for this paper is available online. To view these files, please visit the journal online (http://dx.doi. org/10.1136/bmjopen-2017021366).

Received 8 January 2018 Revised 29 August 2018 Accepted 26 September 2018

Check for updates

(c) Author(s) (or their employer(s)) 2018. Re-use permitted under CC BY-NC. No commercial re-use. See rights and permissions. Published by BMJ.

${ }^{1}$ Institute of Medical Sociology, Health Services Research, and Rehabilitation Science, University Hospital of Cologne, Cologne, Germany

${ }^{2}$ Division for Organizational Health Services Research, Department of Health Services Research, Faculty VI, Carl von Ossietzky University Oldenburg, Oldenburg, Germany

${ }^{3}$ Institute of Medical Statistics and Computational Biology, University Hospital of Cologne, Cologne, Germany

${ }^{4}$ Certification Program Cancer Centers, German Cancer Society, Berlin, Germany

Correspondence to

Sabrina Zeike;

sabrina.zeike@uk-koeln.de

\section{ABSTRACT}

Objectives Nurses are generally found to be vulnerable to burnout, but nurses working in cancer care are even more so, since this profession is characterised by continuous confrontation with suffering and death. This study was designed to identify cut-off scores for job strain, that is, low job control and high job demands, for a sample of nurses working in breast cancer care. The main goal was to find cut-off scores, which predict the risk of nurses of developing a mental disorder from high job strain.

Design The design was a cross-sectional survey study.

Setting The study is based on an employee survey in breast cancer centres in Germany.

Participants 688 nurses received a questionnaire; 329 nurses from 33 hospitals participated in the survey (return rate: $50.2 \%$ ).

Primary and secondary outcome measures Dependent variable: psychological well-being, measured by the WHO5 Well-being Index; independent variables: job control and job demands, measured by the Job Content Questionnaire (JCQ).

Results Multivariable analysis indicates that low job control and high job demands are prognostic factors for low well-being. In a receiver operating curve (ROC) analysis, the cut-off scores, which demonstrated a maximum Youden index, were 34.5 for job control and 31.4 for job demands. The combination of both scales from a logistic regression analysis resulted in an area under the curve of 0.778 . Sensitivity and specificity are $70.3 \%$ and $74.2 \%$, respectively. The total of correct classification was $63.3 \%$.

Conclusion The determined cut-off scores indicate that there is a risk of becoming psychologically ill from a high workload when an individual reaches a score of $\leq 34.5$ for job control and $\geq 31.4$ for job demands. The described method of establishing risk-based cut-off scores is promising for nursing practice and for the field of occupational health. Transferability and generalisability of the cut-off scores should be further analysed.

\section{INTRODUCTION}

The association between job characteristics and health outcomes of employees has been a key issue in occupational health research. ${ }^{1-5}$
Strengths and limitations of this study

- To our knowledge, this is the first study to determine risk-based cut-off scores for Karasek's Job Content Questionnaire (JCQ) scales.

- The study sample is multicentric and population-representative.

- The study scales JCQ and WHO-Five Well-being Index are widely accepted and validated instruments.

- Missing values in certain variables might limit the reliability of the results.

- The study's cross-sectional design limits the value in supporting causal effects and generalisability of the results.

There are well-established models which provide theoretical grounding for this association. The Job Demand-Control (JDC) model is one of the most influential models of work-related stress. Karasek hypothesises in this model that the interplay between job demands (ie, physical and psychological job demands) and job control (ie, skill discretion and decision authority) affects an employee's health outcomes. According to the model, the greatest risk of illness due to stress occurs in workers facing high job strain, defined as a combination of high job demands and low job control. ${ }^{6}$ The buffer hypothesis states that job control can moderate the negative effects of high demands on well-being. A classification in four groups can be made: 'no strain' (low demands/high control), 'active job' (high demands/high control), 'passive job' (low demands/low control) and 'job strain' (high demand/low control).

Working in a high-strain job appears to be associated with lower general psychological well-being, lower job satisfaction, more burnout and more job-related psychological distress. The JDC model has been proven in a multitude of studies. ${ }^{6-9}$ 
Nursing is widely assumed to be a physically and mentally exhausting occupation. Nursing professionals often suffer from negative health outcomes due to chronic work-related stress. ${ }^{10-15}$ As a result, burnout and mental illness is a common phenomenon in nurses. ${ }^{16}$ Previous studies on stress in nurses have demonstrated positive correlations between stress and negative health outcomes. ${ }^{17-20}$ Nursing in cancer care has been identified as a particularly stressful occupation, since this profession is characterised by continuous confrontation with suffering and death. ${ }^{21} 22$ Feeling the helplessness linked with the need to maintain an empathic relationship with patients who are suffering from cancer often leads to particularly stressful and demanding situations. ${ }^{22}$ The demographic changes and the financial pressure in the healthcare sector further lead to a shortage of nursing staff. Therefore, nursing professionals often have a heavy workload to bear. Mental illness in nursing professions is therefore an important problem that organisations must consider in order to prevent absenteeism due to high workload and to ensure a high quality of care. ${ }^{1522}$ To analyse psychological well-being, the WHO-Five Wellbeing Index (WHO-5) questionnaire has been developed, which consists of five items. To investigate associations between job characteristics and health outcomes, the WHO-5 has often been used in the field of occupational stress research. ${ }^{23}$ The diagnostic accuracy of the WHO-5 has been tested in various studies and cut-off scores for the WHO-5 are well established. ${ }^{24} \mathrm{~A}$ score below 13 indicates poor well-being and is an indication for testing for depression under International Classification of Diseases, Tenth Revision. ${ }^{25}$

In practice, there are currently few validated instruments that predict when a health risk exists due to high workloads. Determining cut-off scores for the Job Content Questionnaire (JCQ) can serve to develop early warning indicators to address work-related health risks at an early stage. To our knowledge, there are no cut-off scores yet established for the JCQ. Therefore, this work had two main goals:

1. Analyse the association between job strain and well-being in a group of nursing professionals.

2. Determine cut-off scores for the risk to nurses of developing a psychological illness because of high job strain (ie, low job control and high job demands).

The main research question was as follows: How much workload in terms of high job strain can nurses endure before well-being declines below a psychologically critical threshold?

It was hypothesised that job control has a positive and job demands a negative effect on psychological well-being.

\section{METHODS}

\section{Design}

For the purpose of this paper, we used data from the completed scientific project "introduction of breast centres" (EBRU II) (secondary use of data). In the context of the introduction of the breast centre concept in North Rhine-Westphalia (NRW), the project EBRU II was conducted to provide information on the implementation of requirements, on the staff's perspective and on potential relationships with the quality of care as perceived by patients with breast cancer. The project included a survey of key persons and a survey of the staff involved in breast cancer care. For the purpose of the study, we used data of nursing professionals involved in patient care, since nursing is widely accepted to be an exhausting occupation with low job control and high job demands. ${ }^{101117}$

The survey received ethical approval. From November 2010 to March 2011, a postal survey was sent to the employees working in the units of 49 breast cancer centres in the most populated German state, North Rhine-Westphalia. All employees involved in caring for patients with breast cancer received the questionnaire, additional information on the survey as well as a consent form.

Breast cancer centre hospitals are predominantly concerned with the treatment of patients with breast cancer. A breast cancer centre can consist of only one hospital or it can be a collaboration of hospitals. The breast cancer centre units' management provided us with lists of names of all employees presumably involved in caring for patients with breast cancer. These lists contained diverse employee groups, for example, various physician specialists, nurses, supportive care professionals (eg, physiotherapists or social workers). The survey was designed according to Dillman's Total Design Method, with four contact attempts being made. ${ }^{26}$

\section{Participants}

For the analysis, we used data from 329 nurses from 33 breast cancer centre units, derived from a cross-sectional survey (EBRU II). Nurses in breast cancer care are specialised in the care for patients with breast cancer. The selection of the sample of nurses is presented in figure 1. Of the 2245 hospital employees named on hospitals' lists, 688 were nursing professionals (gross sample). Thirty-two nurses dropped out because they were erroneously included in the gross sample and 327 nurses did not participate or answered less than $30 \%$ of the questionnaire (see figure 1). A total of 329 nurses completed and returned the survey questionnaires (response rate: $50.2 \%$ of the net nurses' sample). The nurses' characteristics are shown in table 1.

\section{Measures}

Data for the employee survey were collected using the "Employee Survey in Centres" questionnaire (German abbreviation: MAZE). ${ }^{27} 28$ The MAZE questionnaire is based on an established German instrument developed and validated by Pfaff $e t ~ a l .^{29}$ It includes questions on work organisation, working conditions and health consequences as well as on sociodemographic characteristics. To control for differences in nurses' characteristics between hospitals, we included data on age and employment status (permanently 


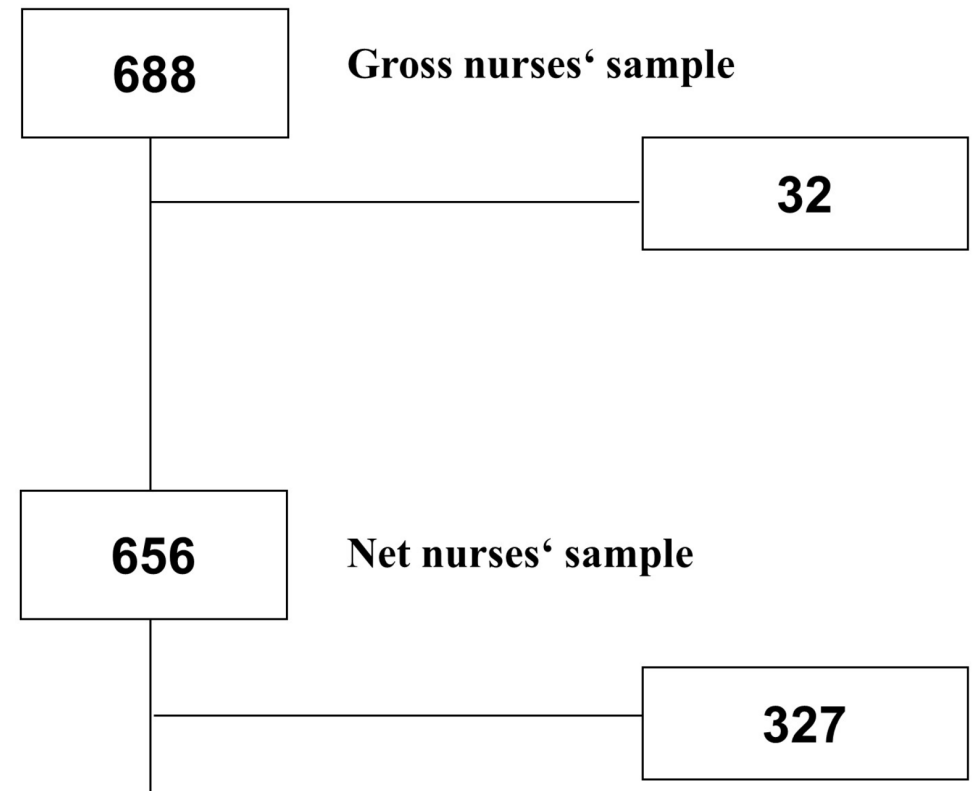

Dropouts:

- not target group (20)

- double (2)

- undeliverable/no longer in breast centre (10)

\section{Dropouts:}

- participation refused (message) (7)

- did not return consent form (7)

- no response (313)

- more than 70 per cent missing (1)

\section{9 \\ Analysis sample (50.2\%)}

Figure 1 Flowchart of the selection of the nurses' sample.

or temporarily employed). This was not controlled for gender due to $98 \%$ of our sample being female.

\section{Dependent variable}

Psychological well-being was measured by using the German version of the WHO-5. ${ }^{30}$ The WHO-5 is a self-administered questionnaire that measures current mental well-being. It covers positively worded items, related to positive mood (good spirits, relaxation), vitality (being active and waking up fresh and rested) and general interests (being interested in things) and includes the following five items: (1) feeling cheerful and in good spirits; (2) feeling calm and relaxed; (3) feeling active and vigorous; (4) feeling fresh and rested when waking up; and (5) feeling interested in day-to-day activities. Each of the five items is rated on a six-point Likert scale from 0 (=notpresent) to 5 (=constantlypresent). Scores are summated, with the raw score ranging from 0 to 25 . The time frame is the previous 2 weeks. In the present study, internal consistency was Cronbach's $\alpha=0.883$ (see table 2 ).

The instrument is among the most widely accepted questionnaires assessing subjective psychological well-being. It has been translated into more than 30 languages and has been used in research studies all over the world. ${ }^{24} 25$ 30-33 The WHO-5 has been validated in a number of studies with regard to both clinical and psychometric validity and has shown to be a reliable measure of emotional functioning and a good screening tool for depression. Receiver operating curve analysis (ROC analysis) showed that the WHO-5 adequately detects depression. ${ }^{33}$ Evidence suggests that a score below 13 on the raw score and a score of less than or equal to 50 on the per cent score are indicative of low mood and an indication for testing for depression. ${ }^{25} 31$

\section{Independent variable}

The JCQ is a questionnaire-based validated instrument designed to measure the JDC model. A charge is made for its utilisation. The authorised German version of the JCQ, originally developed by Karasek et $a l^{34}{ }^{34}$ was used to obtain nurses' job characteristics. ${ }^{34}$ The participants were asked to answer four subscales: psychological job demands, physical job demands, skill discretion and decision authority. Each item had to be answered on a fourpoint Likert scale ranging from 'completely disagree' to 'completely agree'. The values of the subscales 'skill discretion' and 'decision authority' can be added up and constitute the subscale 'job control'. The subscales 'psychological job demands' and 'physical job demands' can be added up to the subscale 'job demands'. Scores are summated with a raw score ranging from 12 to 48 . The variables were scaled following the standard formulas of the JCQ user's guide. ${ }^{35}$

\section{Control variables}

Several variables were thought to be possibly related to our dependent variable. On this account, the variables age, nationality and employment contract were included in our model to control for potential confounding effects. Sex was not included in our model due to $97.7 \%$ of our sample being female.

Age was measured in number of years and, for the purpose of the analysis, divided into six categories $(\leq 29$ 


\begin{tabular}{|c|c|}
\hline Variable & Per cent (n) \\
\hline \multicolumn{2}{|l|}{ Sex } \\
\hline Male & $2.1(7)$ \\
\hline Female & 97.9 (322) \\
\hline Missing & - \\
\hline \multicolumn{2}{|l|}{ Age (mean=43.8) } \\
\hline 18-29 & $9.7(32)$ \\
\hline 30-39 & $17.0(56)$ \\
\hline $40-49$ & $41.0(135)$ \\
\hline $50-59$ & $28.6(94)$ \\
\hline $60-69$ & $1.2(4)$ \\
\hline$\geq 70$ & $0(0)$ \\
\hline Missing & $2.4(8)$ \\
\hline \multicolumn{2}{|l|}{ Nationality } \\
\hline German & $93.9(309)$ \\
\hline Other & $4.3(14)$ \\
\hline German+another citizenship & $1.5(5)$ \\
\hline Missing & $0.3(1)$ \\
\hline \multicolumn{2}{|l|}{ Employment contract } \\
\hline Permanently employed & 97.9 (322) \\
\hline Temporarily employed & $2.1(7)$ \\
\hline Missing & - \\
\hline \multicolumn{2}{|l|}{ Well-being } \\
\hline Low (raw value <13) & $18.2(60)$ \\
\hline High (raw value $\geq 13$ ) & $80.9(266)$ \\
\hline Missing & $0.9(3)$ \\
\hline
\end{tabular}

Job strain (dichotomised, using the median scores for job control and job demands)

\begin{tabular}{ll} 
Low job strain & $20.4(67)$ \\
Active job & $17.6(58)$ \\
Passive job & $22.2(73)$ \\
High job strain & $27.6(91)$ \\
Missing & $12.2(40)$ \\
\hline
\end{tabular}

years; 30-39 years; 40-49 years; 50-59 years; 60-69 years; $\geq 70$ years). Nationality was assessed in three categories (German; Other; Double citizenship). Employment contract was measured in two categories: permanently or temporarily employed.

\section{Statistical analysis}

The survey data were electronically recorded and analysed using IBM SPSS Statistics V.24 and R. The analysing process was conducted in four steps: (1) descriptive analysis and classification into the four groups according to Karasek; (2) multiple linear regression analysis; (3) ROC analysis to determine optimal cut-off scores; (4) validation of cut-off scores.

For missing data, no imputation was performed. The responses were checked for plausibility. Scales with less than $30 \%$ completed items were not formed and the case was excluded. To prevent biases caused by non-random missing values, a category with missing values was included as control variable.

Descriptive analysis and classification of groups according to Karasek

The most common procedure to modify the often-used four-part demand control model diagram is to define employees both above the median on demands and below the median on latitude as the 'high strain group' (job strain quadrant definition). ${ }^{36}$ The job strain variable can then be constructed by dichotomising the scale scores at the median of the sample distribution and combining them into a single variable. ${ }^{37}$ Four categories can be distinguished: 'no strain' (low demands/high control), 'active job' (high demands/ high control), 'passive job' (low demands/low control) and 'job strain' (high demand/low control) (see table 1). The median scores used to categorise between groups were 31 for job control and 35 for job demands.

\section{Multiple linear regression analysis}

A multiple linear regression was conducted to explain the relationship between psychological well-being, job control and job demands. An association model was constructed with well-being (WHO-5) as dependent variable and job

Table 2 Description of the study scales $(n=329)$

\section{WHO-5}

\begin{tabular}{|c|c|c|c|c|c|c|}
\hline Variable & Range & M (SD) & Median & Minimum;maximum & $\begin{array}{l}\text { Missing per cent } \\
\text { (n) }\end{array}$ & $\begin{array}{l}\text { Cronbach's } \\
\alpha \text { value }\end{array}$ \\
\hline \multicolumn{7}{|l|}{ WHO-5 } \\
\hline \multicolumn{7}{|l|}{ JCQ } \\
\hline $\begin{array}{l}\text { Job demands } \\
\text { (ten items) }\end{array}$ & $\begin{array}{l}\text { Scale from } 12 \\
\text { to } 48\end{array}$ & $31.27(5.42)$ & 31.2 & $15 ; 46$ & $8.5(28)$ & 0.810 \\
\hline
\end{tabular}

JCQ, Job Content Questionnaire; WHO-5, WHO-Five Well-being Index. 
control (decision authority and skill discretion) and job demands (physical and psychological demands) as independent variables. The general idea behind association models is to estimate the relationship between variables as accurately as possible. This means that the effect has to be corrected for potential confounders if necessary. ${ }^{38}$

Before model building, it is recommended to check the data for multicollinearity. ${ }^{39}$ We tested the data for multicollinearity using intercorrelations, the variance inflation factor and tolerance.

Potential confounding factors (age, nationality, employment status) as well as missing values were added to the regression model. We conducted a stepwise multiple regression analysis with three steps: In step 1, we added the scales for job control into the regression (model 1). In step 2, the scales for job demands were added (model 2 ). As a third step, control variables were added to the model (model 3) (see table 3).

The multiple linear regression analysis was preliminary to the ROC analysis. It was assumed that job control has a positive correlation with well-being (nurses with high job control have a higher value of well-being) and job demands has a negative correlation with well-being (nurses with high job demands have a lower value of well-being).

\section{Receiver operating characteristic}

ROC analysis was used as an accepted procedure to identify cut-off scores. Cut-off scores are specific values of questionnaires that distinguish between subjects with and without disorders. ${ }^{25}$ Higher sensitivity means fewer false-negatives (undetected disorders), whereas higher specificity means fewer false-positives (cases erroneously diagnosed). ROC was developed in the context of signal detection theory and has been adopted for use in psychological and medical research. In an ROC analysis, the area under the curve (AUC) is calculated to determine the diagnostic value of a test. ${ }^{40}$ The area under the ROC curve is an indicator of test performance, the sensitivity (true positive rate) and specificity (true negative rate) of each potential cut-off score are calculated. ${ }^{41} \mathrm{~A}$ test with an AUC of 0.5 indicates that the examined instrument does not discriminate between two states of interest (eg, sick/not sick), whereas a test with an AUC of 1 is considered to have perfect diagnostic accuracy. For non-medical procedures, AUCs of 0.65-0.70 are considered good. ${ }^{40}$ The optimal cut-off score is defined as the point on the ROC curve, which is the furthest from the diagonal. For this optimal cut-off score, the Youden index reaches its maximum. ${ }^{43}$ In order to obtain a good trade-off between false-positive and false-negative decisions, the cut-off score which demonstrated a maximum Youden index ( $Y=$ sensitivity+specificity-1) was selected.

As a common approach, the data set was split randomly into two parts (2:1). ROC analysis was performed in the first part of the study sample (two-thirds of the sample, 'trainings set'). The predictive accuracy was tested in the second part (one-third of the sample, "validation set'). This approach is recommended because it tends to give realistic results due to the two data sets being very similar. ${ }^{44}$ ROC analyses are used to evaluate how well a system predicts a binary classifier system. In this case, the WHO-5 was used as criterion standard (cut-off score $<13$ ). The determined cut-off scores represent a specific value of the raw score of job control and job demands and are used to distinguish between employees with or without a risk of becoming psychologically ill from a high job strain, that is, low job control and high job demands. New variables were formed by dichotomising the subscales into above the cut-off score and below the cut-off score.

After determining cut-off scores for job control and job demands, we conducted an ROC analysis with the combination of both scales from a logistic regression analysis. The cut-off scores were then validated in the validation set, using a cross-tab, showing sensitivity and specificity of the identified cut-off scores and the number of correct and false classifications.

\section{Patient and public involvement statement}

The present study did not involve any patients or the public.

Table 3 Standardised coefficients (SE) from the multiple linear regression analysis with psychological well-being as the dependent variable $(n=329)$

\begin{tabular}{|c|c|c|c|c|c|c|}
\hline & Model 1 & & Model 2 & & Model 3 & \\
\hline Predictor & Beta & $P$ values & Beta & $P$ values & Beta & $P$ values \\
\hline Skill discretion & $.204^{\star *}$ & .002 & $.262^{\star \star \star}$ & .000 & $.273^{\star \star \star}$ & .000 \\
\hline Psychological demands & & & $-0.257^{\star \star \star}$ & .000 & $-0.252^{\star \star \star}$ & .000 \\
\hline Physical demands & & & .030 & .631 & .027 & .671 \\
\hline Adjusted $\mathrm{R}^{2}$ & $.108^{\star \star \star}$ & & $.161^{\star \star \star}$ & & $.154^{\star \star \star}$ & \\
\hline$\Delta \mathrm{R}^{2}$ & $.115^{\star \star \star}$ & & $.057^{\star \star \star}$ & & $.014^{\star \star \star}$ & \\
\hline
\end{tabular}

Control variables are not shown; all control variables were not significant.

$n=326 ;{ }^{*} P \leq 0.05 ;{ }^{\star \star} P \leq 0.01 ;{ }^{\star \star \star} P \leq 0.001$. 


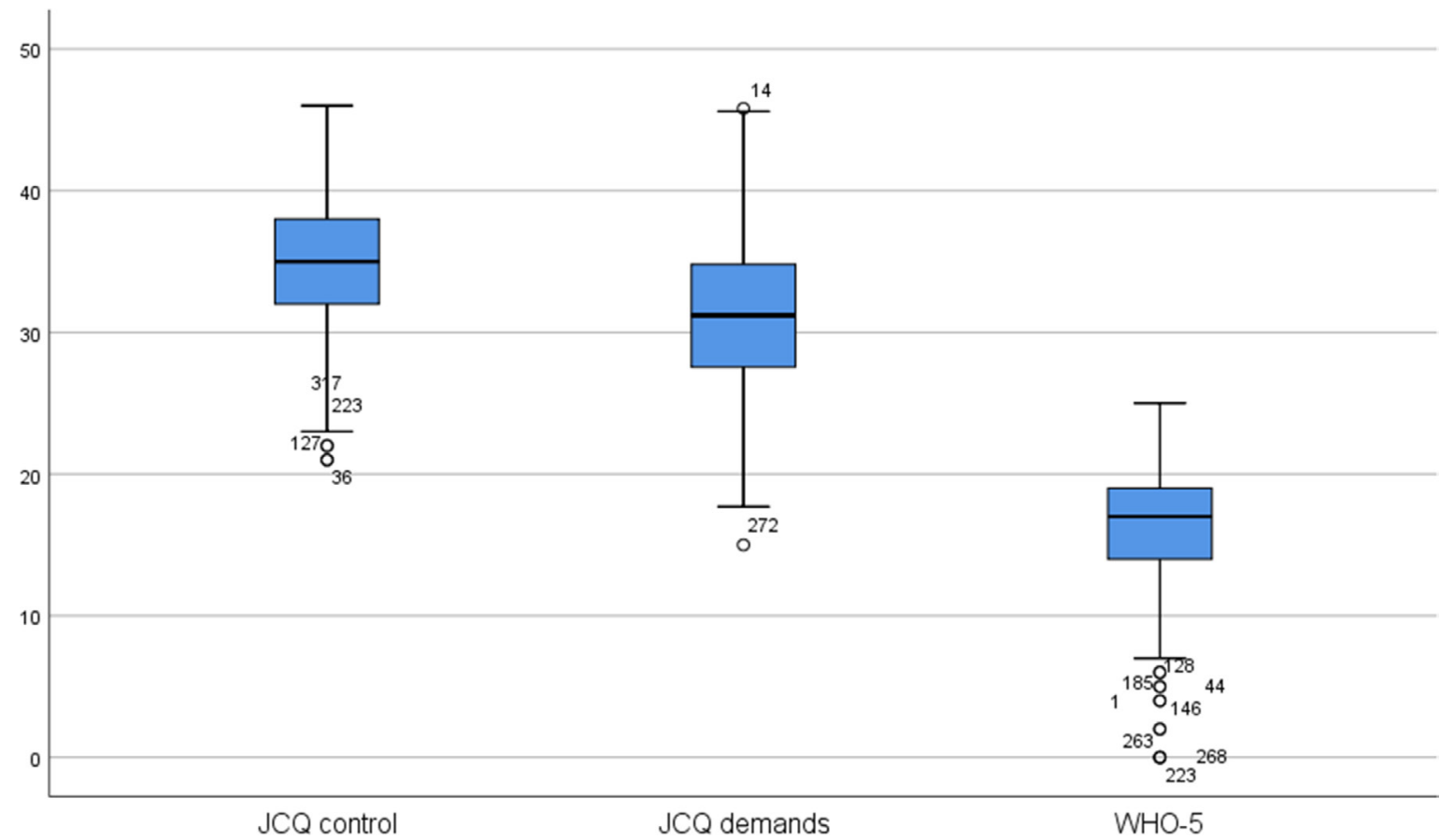

Figure 2 Boxplots for the study scales psychological well-being (WHO-Five Well-being Index (WHO-5)), job control and job demands ( $n=329)$. JCQ, Job Content Questionnaire.

\section{RESULTS}

\section{Descriptive findings}

Data from 329 hospital nurses remained for analysis (see figure 1). Key sample features are presented in table 1 . In our sample, $97.9 \%$ are women and $2.1 \%$ are men. The mean age was 43.8 years. Of the total sample, $93.9 \%$ are German, $4.3 \%$ of the participants have other nationalities, $1.5 \%$ a double citizenship. The percentage of permanently and temporarily employed nurses is $97.9 \%$ and $2.1 \%$, respectively. Of the 329 nurses, $18.2 \%$ had a psychological well-being below 13, 80.9\% had a score of 13 or above (see table 1). Both job control and job demands were significantly correlated with psychological well-being. Boxplots for the scales well-being, job control and job demands are shown in figure 2.

According to Karasek, the participants were categorised into four groups. The median was used to dichotomise between high/low job control and high/low job demands. The median for job control was 35 and 31 for job demands. $27.6 \%$ were classified as having high job strain and $20.4 \%$ as low job strain; $22.2 \%$ were categorised as having a passive job and $17.61 \%$ in an active job (see table 1).

\section{Factors associated with psychological well-being}

The results from the regression models are presented in table 3. In model 1, the associations of job control (skill discretion and decision authority) with psychological well-being are analysed. Eleven per cent of the variance in psychological well-being can be explained $(\mathrm{p}<0.001$; $R^{2}$ adj=0.108). After introducing job demands (psychological and physical demands) into the model, $16 \%$ of the variance can be explained (model 2$)\left(\mathrm{p}<0.001 ; R^{2}\right.$ adj=0.161).
The difference in delta is significant $\left(\mathrm{p}<0.001 ; \Delta R^{2} 0.57\right.$ ). The association of skill discretion with psychological wellbeing persists. Psychological demands and skill discretion have the strongest association with the nurses' psychological well-being (beta $=-0.252$ for psychological demands and 0.273 for skill discretion). In model 3 , the control variables were added. The difference in $\Delta R^{2}$ is 0.14 $(p<0.001)$. None of the control variables were associated with psychological well-being.

\section{Identification and validation of sensitive and specific cut-off scores}

We conducted three ROC analyses in our trainings set $(\mathrm{n}=215)$ : (1) for job control, (2) for job demands and (3) for the combination of both scales from a logistic regression analysis.

For the JCQ scale job control, ROC analysis resulted in an AUC of 0.721 . On a scale from 12 to 48, the Youden index was maximal for the cut-off score of 34.5 . The sensitivity for this cut-off score is $74 \%$, the specificity $63 \%$ (see figure 3 ). All cases with a raw score of $<34.5$ were classified as 'low job control' (1); all other cases were classified as 'high job control' ( 0$)$.

For job demands, the AUC was 0.685. On a scale of 12 to 48 , the cut-off score, which demonstrated a maximum Youden index, was 31.4. The cut-off score has a sensitivity of $79 \%$ and a specificity of $58 \%$ (see figure 3 ). Cases with a raw score of $<31.4$ were classified as 'low job demands' (0); all other cases were classified as 'high job demands' (1).

For the third ROC analysis, we used the predicted probabilities of a logistic regression model, containing the two scales job control and job demands. The analysis resulted 


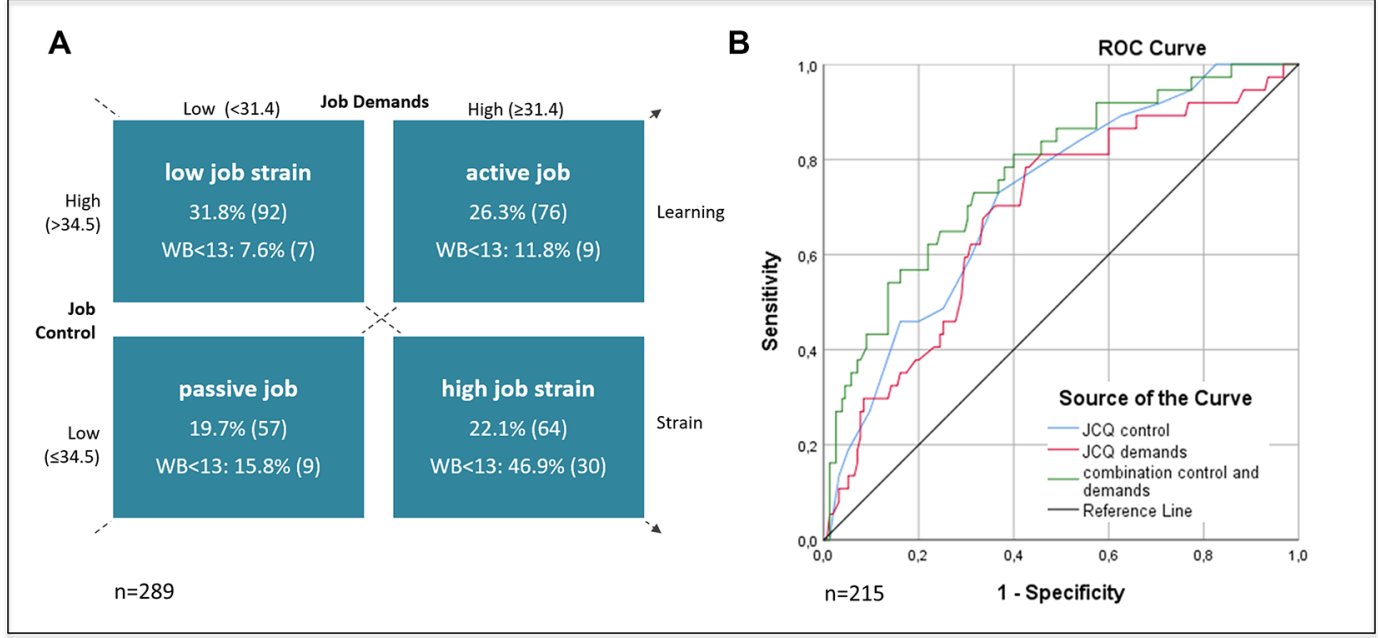

Figure 3 (A) Classification in groups of job strain, according to Karasek ${ }^{35}$; valid per cent (n); subjects below the crucial cut-off of 13 for well-being (WB) for each pattern, valid per cent (n). (B) Receiver operating characteristic (ROC) curve in which the truepositive rate is plotted against the false-positive rate for job control, job demands and the combination of both (analysis in the trainings set; $n=215$ ).

in an AUC of 0.778. The cut-off score for the predicted probabilities with a maximum Youden Index was 0.238. Sensitivity and specificity were $70.3 \%$ and $74.2 \%$, respectively. The total of correct classifications (ie, true positives+true negatives) for the combination of both scales was $63.3 \%$ (see table 4 ).

The results of ROC analyses were then used to reclassify the groups according to Karasek and to determine the number of nurses with high job strain. The results show that 64 nurses $(22.1 \%)$ are at risk due to high job strain (see figure 3 ).

\section{DISCUSSION}

The main goal of this study was to determine cut-off scores for the scales job control and job demands of Karasek's

Table 4 Cross-tab classification for predictive values and the external criterion psychological well-being in the validation set

\begin{tabular}{|c|c|c|c|}
\hline & \multicolumn{2}{|c|}{$\begin{array}{l}\text { Combination job } \\
\text { control and demands }\end{array}$} & \multirow[t]{2}{*}{$\begin{array}{l}\text { Positives+true } \\
\text { negatives }\end{array}$} \\
\hline & $\begin{array}{l}\text { Predicted } \\
\text { good well- } \\
\text { being }\end{array}$ & $\begin{array}{l}\text { Predicted } \\
\text { poor well- } \\
\text { being }\end{array}$ & \\
\hline $\begin{array}{l}\text { Good } \\
\text { psychological } \\
\text { well-being }\end{array}$ & $65.4 \%$ & $34.6 \%$ & $65.4 \%$ \\
\hline $\begin{array}{l}\text { Poor } \\
\text { psychological } \\
\text { well-being }\end{array}$ & $38.9 \%$ & $61.1 \%$ & $61.1 \%$ \\
\hline Total percentage & & & $63.3 \%$ \\
\hline
\end{tabular}

JCQ in a sample of nurses in breast cancer care in Germany. The results show there is a high risk of having a poor psychological well-being when an individual reaches a score of 34.5 or below for job control and a score of 31.4 or higher for job demands. The AUCs, 0.721 for job control and 0.685 for job demands and 0.778 for the combination of both, are considered good for non-medical procedures. With a total of $63.3 \%$ correct classifications (ie, true positives+true negatives), the scales proved to have a satisfactory capacity to predict poor well-being.

Using the new determined cut-off scores for classification between the groups of Karasek, in the present study, $22.1 \%$ of the nurses were categorised as having a high job strain and $31.8 \%$ as low job strain; $26.3 \%$ were categorised as having an active job and $19.7 \%$ a passive job.

In our study sample, $97.7 \%$ were women. Since nurses working in cancer care are predominantly women, our sample is representative for this particular group. ${ }^{22} 4546$ Our study has shown that nurses are exposed to a high level of job strain. Screening tools for practice to recognise high health-endangering strains are therefore particularly important for this specific group. In times of shortage of skilled nurses, it is particularly important for hospitals to keep their nursing professionals healthy.

ROC analyses can only be performed for tests that provide either continuous or rating scale data. Since job strain is a dichotomous variable, calculated from job control and job demands, it is not possible to determine a cut-off score for job strain. However, the cut-off scores for job control and job demand can be used to classify between the groups of Karasek and to determine the number of persons at risk.

\section{Strength and limitations}

Strengths of the study are a good database and a homogeneous sample group. The WHO Well-being Index and the JCQ are well validated and scientifically accepted scales. 
Moreover, the study has a good theoretical basis, namely the JDC model. To our knowledge, this is the first study to determine optimal cut-off scores for Karasek's JCQ by ROC analysis for the prevention of mental disorders.

Nonetheless, the study has several limitations, which may have biased the results. Among these limitations is the cross-sectional study design and missing values in certain variables, which limited the reliability of the results. The cut-off scores are population-specific and the generalisability of the results is not naturally given. Furthermore, regression analysis has shown that the JCQ and the other variables included in our model can only predict a small part of the variance of psychological well-being.

The predictive power of the determined cut-off scores coincides with the results of other studies. ${ }^{47}$ However, it is noteworthy that there are only a few comparable studies that have determined (risk-based) cut-off scores in the field of occupational health and health promotion. In contrast to many other studies, the external criterion was not a gold standard (eg, another test, measuring job control and job demands), but psychological well-being as a dependent variable. The determined cut-off scores, therefore, differ from other scores by not discriminating between, for example, ill/not ill, but between the high/ low risk of poor psychological well-being.

\section{Practical implications}

The determined cut-off scores can provide a useful method in the practice of occupational health promotion and can help to identify persons/departments who are particularly at risk due to high job strain. The ROC curve comprises all possible combinations of sensitivity and specificity at all possible values. This offers the opportunity to assess the optimal, population-specific cut-off score to be used in practice.

The cut-off scores are easy to implement via employee surveys and can be a tool in assessing the impact of preventive measures. The method of establishing risk-based cut-off scores is therefore promising for nursing practice and generally for the field of occupational health. However, it is important to note that, for data protection reasons, it is often not possible to set individual cut-off scores at the personal level. The individual cut-off scores should therefore be calculated on an aggregated level, for example, per department. In practice, decision-makers can identify particularly stressed departments/areas and initiate preventive measures, within occupational health promotion. The described method can in this context be useful as a screening instrument, which, in the case of a high risk, should be followed by further assessments.

For nursing practice, the results of the current study show that a high number of nurses working in cancer care are exposed to a high level of strain. Nurses generally have a high level of job demands and a low level of job control, which makes them a vulnerable target group. ${ }^{10-15}$ The development towards more participatory decision-making, better methods of providing meaningful feedback and opportunities to reduce high work demands could be a valuable contribution to nursing practice. The revealed method to identify risk-based cut-off scores for job strain can help in nursing practice to detect and track in time the amount of nurses at particular risk.

For the workplace environment of cancer care nurses, it is especially important to track these risks due to their high level of job strain. In addition, the method described in this article can be used as a screening tool in practice by clinicians and healthcare professionals to observe the situation of employees over time or to evaluate the interventions.

\section{CONCLUSION}

In this study, we presented a method of determining cut-off scores for the risk to get psychologically ill from high job strain (i.g. low job control and high job demands). We used the WHO-5 scale as discriminator between persons at risk/not at risk. The results show that the WHO-5-scale is useful to set risk-based cut-off scores. In clinical practice, efforts to reduce workload and increase decision latitude may prevent the development of low psychological well-being. Especially among the group of cancer care nurses, who are exposed to high job strain in their daily work, these efforts are important in order to maintain long-term health and ability to work. In general, the rate of correct classifications is, with $63.3 \%$, too small to justify interventions. But the described method can be useful as a screening instrument, followed by further assessments.

In further studies, the transferability and generalisability of the cut-off scores should be tested. Furthermore, longitudinal studies are necessary to confirm the results and the usability of the determined cut-off scores. Since working conditions are very different within different occupational groups, it is to be assumed that the cut-off scores are population-specific.

Acknowledgements We would like to thank all hospitals and employees who kindly agreed to participate in the survey. We are also grateful to the Landeszentrum Gesundheit Nordrhein-Westfalen (Centre for Health North RhineWestphalia), Deutsche Krebshilfe (German Cancer Aid) and Köln Fortune (grant from the University Hospital of Cologne) for providing financial support. We would also like to thank CK and LA for the successful completion of the project and the collection of data and Markus Alich, Dorothee Possel and Stefanie Sauter for technical support.

Contributors Data were collected by CK and LA. SZ carried out data analysis under the supervision of LL, CS and HP. SZ wrote the manuscript that was then revised by the coauthors. All authors have approved the final version of the manuscript.

Funding This work was supported by the Landeszentrum Gesundheit NordrheinWestfalen (Centre for Health North Rhine-Westphalia), the German Cancer Aid and Köln Fortune (grant from the University Hospital of Cologne).

Competing interests None declared.

Patient consent Not required.

Ethics approval Ethics Committee of the Medical Faculty of the University of Cologne.

Provenance and peer review Not commissioned; externally peer reviewed.

Data sharing statement Participant data will not be shared.

Open access This is an open access article distributed in accordance with the Creative Commons Attribution Non Commercial (CC BY-NC 4.0) license, which permits others to distribute, remix, adapt, build upon this work non-commercially, 
and license their derivative works on different terms, provided the original work is properly cited, appropriate credit is given, any changes made indicated, and the use is non-commercial. See: http://creativecommons.org/licenses/by-nc/4.0/.

\section{REFERENCES}

1. Oshio T, Inoue A, Tsutsumi A. Examining the mediating effect of work-to-family conflict on the associations between job stressors and employee psychological distress: a prospective cohort study. BMJ Open 2017;7:e015608.

2. Siegrist J. Stress in the workplace. The New Blackwell Companion to Medical Sociology 2016:268.

3. Cottini E, Lucifora C. Mental health and working conditions in Europe. ILR Review 2013;66:958-88.

4. Luchman JN, González-Morales MG. Demands, control, and support: a meta-analytic review of work characteristics interrelationships. J Occup Health Psychol 2013;18:37-52.

5. Ganster DC, Rosen CC. Work stress and employee health: A multidisciplinary review. Journal of Management 2013;39:1085-122.

6. Karasek RA. Job demands, job decision latitude, and mental strain: implications for job redesign. Administrative Science Quarterly 1979;24:285.

7. Bakker AB, Demerouti E, Sanz-Vergel Al. Burnout and work engagement: The JD-R Approach. Annual Review of Organizational Psychology and Organizational Behavior 2014;1:389-411.

8. Häusser JA, Mojzisch A, Niesel M, et al. Ten years on: A review of recent research on the Job Demand-Control (-Support) model and psychological well-being. Work Stress 2010;24:1-35.

9. Carayon P. A longitudinal test of Karasek's Job Strain model among office workers. Work Stress 1993;7:299-314.

10. Pisanti $R$, van der Doef M, Maes $S$, et al. How changes in psychosocial job characteristics impact burnout in nurses: a longitudinal analysis. Front Psychol 2016;7:1082.

11. Pisanti $R$, van der Doef $M$, Maes $S$, et al. Job characteristics, organizational conditions, and distress/well-being among Italian and Dutch nurses: a cross-national comparison. Int J Nurs Stud 2011;48:829-37.

12. Dall'Ora C, Griffiths $P$, Ball J, et al. Association of $12 \mathrm{~h}$ shifts and nurses' job satisfaction, burnout and intention to leave: findings from a cross-sectional study of 12 European countries. BMJ Open 2015;5:e008331.

13. Zhang XC, Huang DS, Guan P; Job burnout among critical care nurses from 14 adult intensive care units in Northeastern China: a cross-sectional survey. BMJ Open 2014;4:e004813.

14. Khamisa N, Peltzer K, Oldenburg B. Burnout in relation to specific contributing factors and health outcomes among nurses: a systematic review. Int J Environ Res Public Health 2013;10:2214-40.

15. Adriaenssens J, De Gucht V, Maes S. Determinants and prevalence of burnout in emergency nurses: a systematic review of 25 years of research. Int J Nurs Stud 2015;52:649-61.

16. Ríos-Risquez MI, García-Izquierdo M, Sabuco-Tebar EL, et al. An exploratory study of the relationship between resilience, academic burnout and psychological health in nursing students. Contemp Nurse 2016;52:430-9.

17. McVicar A. Workplace stress in nursing: a literature review. J Adv Nurs 2003;44:633-42

18. Lin SH, Liao WC, Chen MY, et al. The impact of shift work on nurses' job stress, sleep quality and self-perceived health status. J Nurs Manag 2014;22:604-12.

19. Happell B, Dwyer T, Reid-Searl K, et al. Nurses and stress: recognizing causes and seeking solutions. J Nurs Manag 2013;21:638-47.

20. Edwards D, Burnard P, Coyle D, et al. Stress and burnout in community mental health nursing: a review of the literature. $J$ Psychiatr Ment Health Nurs 2000;7:7-14.

21. Wilkinson SM. Stress in cancer nursing: does it really exist? J Adv Nurs 1994;20:1079-84.

22. Quattrin R, Zanini A, Nascig E, et al. Level of burnout among nurses working in oncology in an Italian region. Oncol Nurs Forum 2006;33:815-20.

23. Schütte S, Chastang JF, Malard L, et al. Psychosocial working conditions and psychological well-being among employees in 34 European countries. Int Arch Occup Environ Health 2014;87:897-907.

24. Topp CW, Østergaard SD, Søndergaard S, et al. The WHO-5 Well-Being Index: a systematic review of the literature. Psychother Psychosom 2015;84:167-76.

25. Löwe B, Spitzer RL, Gräfe K, et al. Comparative validity of three screening questionnaires for DSM-IV depressive disorders and physicians' diagnoses. J Affect Disord 2004;78:131-40.

26. Dillman DA. Mail and telephone surveys: The total design method: Wiley New York, 1978.

27. Ansmann L, Kowalski C, Ernstmann N, et al. Do breast cancer patients receive less support from physicians in German hospitals with high physician workload? A multilevel analysis. Patient Educ Couns 2013;93:327-34.

28. Pfaff H, Ansmann L, Kowalski C, et al. Mitarbeiterfragebogen für Zentren (MAZE): Kennzahlenhandbuch. Köln: Institut für Medizinsoziologie, Versorgungsforschung und Rehabilitationswissenschaft (IMVR), 2013

29. Pfaff H, Pühlhofer F, Brinkmann A, et al. Forschungsbericht 4-2004: Der Mitarbeiterkennzahlenbogen (MIKE): Kompendium valider Kennzahlen Kennzahlenhandbuch Köln: Klinikum der Univ. zu Köln, Inst. und Poliklinik für Arbeitsmedizin, Sozialmedizin und Sozialhygiene, 2004.

30. WHO. WHO Collaborating Center for Mental Health (1998) WHO (Five) well2being index. Geneva: World Health Organization.

31. WHO Regional Office for Europe. Wellbeing measures in primary health care/The depcare project: Report on WHO Meeting 1998.

32. Krieger T, Zimmermann J, Huffziger S, et al. Measuring depression with a well-being index: further evidence for the validity of the WHO Well-Being Index (WHO-5) as a measure of the severity of depression. J Affect Disord 2014;156:240-4.

33. Heun R, Bonsignore M, Barkow $\mathrm{K}$, et al. Validity of the five-item WHO Well-Being Index (WHO-5) in an elderly population. Eur Arch Psychiatry Clin Neurosci 2001;251:27-31.

34. Karasek R, Brisson C, Kawakami N, et al. The Job Content Questionnaire (JCQ): an instrument for internationally comparative assessments of psychosocial job characteristics. J Occup Health Psychol 1998;3:322-55.

35. Karasek R. Job content questionnaire and user's guide, 1985

36. Landsbergis PA, Schnall PL, Warren K, et al. Association between ambulatory blood pressure and alternative formulations of job strain. Scand J Work Environ Health 1994;20:349-63.

37. Karasek R, Theorell T. stress Healthy work: productivity and the reconstruction of working life: Basic books, 1992.

38. Twisk JWR. Applied Multilevel Analysis: A Practical Guide. Cambridge: Cambridge University Press, 2006.

39. Cohen J. Applied multiple regression/correlation analysis for the behavioral sciences. 3rd edn. New York: Routledge / Taylor \& Francis, 2009.

40. Swets JA, Pickett RM. Evaluation of diagnostic systems: Methods from signal detection theory Academic. New York, 1982.

41. Sackett DL, Haynes RB, Guyatt GH, et alln: Tugwell P, Sackett DL, Haynes RB, Guyatt GH, . The interpretation of diagnostic data, 1991:69-152.

42. Greiner M. Serodiagnostische Tests: Evaluierung und Interpretation in der Veterinärmedizin und anderen Fachgebieten. Berlin, New York: Springer, 2003

43. Fluss R, Faraggi D, Reiser B. Estimation of the Youden Index and its associated cutoff point. Biom J 2005;47:458-72.

44. Altman DG, Vergouwe $Y$, Royston $P$, et al. Prognosis and prognostic research: validating a prognostic model. BMJ 2009;338:b605.

45. Kaneko M, Ryu S, Nishida H, et al. Nurses' recognition of the mental state of cancer patients and their own stress management - a study of Japanese cancer-care nurses. Psychooncology 2013;22:1624-9.

46. Poulsen MG, Poulsen AA, Baumann KC, et al. A cross-sectional study of stressors and coping mechanisms used by radiation therapists and oncology nurses: Resilience in Cancer Care Study. $J$ Med Radiat Sci 2014;61:225-32.

47. Jung J, Nitzsche A, Neumann M, et al. The Worksite Health Promotion Capacity Instrument (WHPCI): development, validation and approaches for determining companies' levels of health promotion capacity. BMC Public Health 2010;10:550. 